\title{
ESQUERDA NACIONAL E EMPRESÁRIOS NA AMÉRICA LATINA
}

\author{
Luiz Carlos Bresser-Pereira
}

Podem os empresários ser parte de um partido e de um governo de esquerda? Para responder a essa pergunta é necessário saber o que entendemos por esquerda e direita. Meu conceito de esquerda e direita tem como critérios a justiça social e a ordem pública, de um lado, e o reconhecimento ou não da necessidade de intervenção do Estado na economia, de outro. Enquanto alguém de direita prioriza sempre a ordem em relação à justiça, quem é de esquerda está disposto a arriscar a ordem em nome da justiça social; enquanto o conservador é hoje um neo ou ultraliberal, o progressista defende um grau razoável de intervenção do Estado para corrigir as falhas alocativas e distributivas do mercado. Há muitos tipos de esquerda, mais do que tipos de direita, provavelmente porque esta, além dos valores e idéias, tem o capital para uni-la, enquanto a esquerda só tem valores e idéias. Podemos distinguir pelo menos quatro tipos de esquerda: a extrema esquerda, a esquerda utópica, a esquerda burocrático-sindical e a centro-esquerda. A extrema esquerda é revolucionária, não vendo na democracia existente senão uma forma de dominação: pretende assumir o poder revolucionariamente para, em seguida, implementar o que denomina socialismo, mas que é mais correto chamar de 
estatismo. A esquerda utópica prefere não disputar o poder para manter seus ideais socialistas e para poder ser uma força crítica dentro da sociedade; o melhor exemplo desse tipo de esquerda é, hoje, o movimento "outromundialista", que se formou a partir dos Fóruns Sociais Mundiais: seus participantes mais representativos afirmam que não aspiram ao poder, mas querem ser a consciência crítica das sociedades capitalistas contemporâneas. A esquerda burocrático-sindical joga o jogo democrático e tem bases fortes na burocracia do Estado e nos sindicatos. Finalmente, a centro-esquerda reconhece a impossibilidade de uma transição para o socialismo dentro de um prazo previsível, e, usando uma frase de Michel Rocard, trata de "governar o capitalismo mais competentemente que os capitalistas". Ou seja, é uma esquerda reformista que, durante o século vinte, foi social-democrata, mas que está se transformando em uma centro-esquerda social-liberal, na medida em que os partidos de esquerda na Europa vêm reformando suas economias e seu Estado no sentido de manter a garantia aos direitos sociais e aprofundar a igualdade, ao mesmo tempo que aceitam um papel mais ativo de mercados regulados na coordenação do sistema.

Uma segunda pergunta, porém, é necessária: pode essa esquerda ser nacional? Na América Latina, depois de um longo período de hegemonia das idéias de direita e globalistas, que se tornaram dominantes na região na segunda metade dos anos 1980, a esquerda e o nacionalismo democrático estão de volta. Nos últimos três anos, foram eleitos governos de esquerda e nacionalistas no Brasil, na Argentina, na Venezuela, no Uruguai e na Bolívia. Entende-se, aqui, por nacionalismo a ideologia da formação e sustentação do Estado-nação. O nacionalismo democrático e moderadamente liberal que está surgindo compreende a globalização como a competição generalizada, em escala mundial, das empresas apoiadas por seus respectivos países ou Estados-nação, e, sem rejeitar os conflitos, defende uma razoável solidariedade das classes quando 
se trata de competir internacionalmente. $\mathrm{O}$ globalismo ou o cosmopolitismo, por sua vez, entende que na globalização os Estados nacionais perderam autonomia e relevância, rejeita a idéia de uma competição generalizada e espera que seu país conte com o apoio ou a ajuda dos países ricos. O nacionalismo não é necessariamente de esquerda. Historicamente, foi antes uma ideologia burguesa que se somou à ideologia liberal para que se formassem os modernos Estados-nação. No entanto, desde que a Guerra Fria levou as burguesias nacionais a se identificarem com os Estados Unidos para assim fazerem frente às ameaças comunistas locais, o nacionalismo tendeu a ser crescentemente adotado por partidos de centro-esquerda. A Guerra Fria já terminou há quase 20 anos, mas só recentemente os empresários estão se dando conta de que seus interesses mudaram e que, agora, faz mais sentido competir internacionalmente em vez de se subordinar e aproveitar as frestas, como supõe a ideologia globalista e cosmopolita.

\section{A luta pelo centro}

Na discussão do conceito de esquerda, é essencial debater o problema do centro. No quadro das sociedades modernas, os agrupamentos políticos que se autodenominam de centro são sempre de direita, ou de centro-direita. Podemos e devemos pensar em uma escala ideológica que vai da extrema direita para a extrema esquerda, passando pela direita, a centro-direita, a centro-esquerda e a esquerda. Ficamos, assim, como uma escala de seis formações políticas, mas sem um centro. Nessa escala, o centro é inexistente; como ponto virtual, porém, é fundamental. O grande objetivo tanto da esquerda quanto da direita é conquistar o centro, porque, quando o conquista, se torna governo. Como esse centro se move ciclicamente ora para um lado ora para outro, toda a luta ideológica entre a esquerda e a direita nas democracias modernas se trava em torno de empurrar esse centro mais para a esquerda ou mais para a direita. 
Os movimentos do centro são, naturalmente, pendulares: ora o centro caminha para a esquerda, como aconteceu no mundo a partir da Grande Depressão dos anos 1930, ora caminha para a direita, como ocorreu a partir de meados dos anos 1970. Esses movimentos ocorrem à medida que as propostas de governo de um ou de outro grupo se esgotam, e os eleitores situados mais próximos ao centro deslocam-se na direção oposta àquela dominante. Por outro lado, é preciso considerar que o centro varia geograficamente. Nos Estados Unidos, onde nunca houve um movimento socialista forte, o centro está muito mais à direita do que na Grã-Bretanha, que, por sua vez, está mais à direita do que na França, na Alemanha, ou na Espanha. Essa diferença geográfica de colocação do centro deve-se a razões de ordem histórica que não importa aqui discutir. Importa deixar claro o fato de que, se aceitarmos essa variação no centro, o conceito de esquerda e direita torna-se relativo. Políticas consideradas de esquerda nos Estados Unidos poderão ser consideradas de direita na França. Os políticos progressistas ou de esquerda americanos são geralmente associados ao Partido Democrata e denominados "liberais", numa referência ao século dezoito e começo do dezenove, quando os liberais eram progressistas lutando em nome da burguesia contra os conservadores ainda aliados à aristocracia.

Ao afirmar que o centro se move no tempo e varia geograficamente de país para país, reconheço uma limitação na definição teórica que ofereci inicialmente. Se for estrito em definir esquerda e direita em relação à ordem e à justiça, não faria sentido essa variação. Arriscar a ordem, admitir a ação de movimentos sociais, como greves, restringir sem violência ações ilegais de outros movimentos sociais, como as invasões, que, no Brasil, os sem-terra e os sem-teto com freqüência promovem, e apoiar suas reivindicações, seria sempre de esquerda. Em contrapartida, defender a lei a qualquer preço, usar da autoridade tradicional e religiosa para justificar posições políticas e morais seria sempre de direita. Isso, porém, é ver- 
dadeiro até certo ponto. Nas questões sociais, o princípio da razoabilidade deve sempre prevalecer, e esse princípio rejeita distinções claras e precisas entre o branco e o preto. A realidade social é ambígua, assim como o ser humano. A direita tende a pressupor que o ser humano é, por natureza, egoísta ou auto-interessado; a esquerda, a pensá-lo como generoso ou capaz de generosidade. Na verdade, o ser humano é intrinsecamente contraditório e, portanto, ambíguo. Ele nasce com duas necessidades fundamentais e contraditórias: de um lado, o instinto da sobrevivência o faz individualista e egoísta; de outro, o instinto da convivência o torna solidário e cooperativo. Toda a sociedade humana baseia-se nessa ambigüidade, e, por isso, os cientistas sociais enfrentam tanta dificuldade em prever seu comportamento.

Se o centro varia geograficamente, seria interessante perguntar o que acontece com o centro no Brasil ou na América Latina. Está mais à esquerda ou mais à direita do que nos países desenvolvidos da Europa continental? Não sei responder com clareza, porque a divisão entre esquerda e direita enfrenta uma dificuldade fundamental na região. Não quero falar por toda a América Latina, onde a esquerda hoje está presente no governo da Argentina, do Uruguai, do Chile, da Venezuela, da Bolívia e do Brasil. Conforme observou Wilfredo Lozano (2005: 145), "a esquerda hoje no poder resulta ser um complexo produto de sua reacomodação reformadora, o que a obrigou a girar para o centro". Quanto, entretanto, girar para o centro? E o giro é apenas para o centro ou para a direita? Ditmar Dimoser (2005: 28), escrevendo sobre a democracia na América Latina, pergunta: "estará o futuro latino-americano caracterizado por democracias sem democratas?" Tal pergunta envolve um paradoxo absoluto. No caso do Brasil, em relação não à democracia, mas à esquerda, a questão está dominada por um outro paradoxo que talvez não esteja ausente do restante da América Latina: a esquerda ganha as eleições, à medida que partidos de esquerda ou de centro-esquerda alcançam 
a maioria no Parlamento, mas não governa. Denomino esse fenômeno de "paradoxo da esquerda". Será ele verdadeiro? E, se for, há uma explicação para ele, ou é um paradoxo puro?

Para responder a essas perguntas, e tomando o Brasil apenas como base de minha análise, parto do pressuposto de que a ideologia é determinante do voto. Esse pressuposto teórico foi colocado em dúvida por uma série de analistas internacionais, geralmente de filiação conservadora, que também tendem a negar a relevância da diferença esquerda-direita. No entanto, as pesquisas deixaram claro que os eleitores, embora não tenham uma estrutura ideológica definida, para a qual seriam necessários conhecimentos que eles não possuem, são possuidores de uma identificação ideológica suficiente que lhes permite distinguir as posições de esquerda ou de direita, progressistas ou conservadoras. Singer (1999) testou essa hipótese em relação ao Brasil, e a viu confirmada. O Brasil transitou para a democracia em 1985. Desde então, os partidos que dominam o 88 parlamento brasileiro (pela ordem histórica, o PMDB, o PSDB e o PT) sempre se autodefiniram como partidos de esquerda - os dois primeiros, de centro-esquerda, o último, de esquerda - e, juntamente com os pequenos partidos de esquerda, lograram a maioria na Câmara dos Deputados ${ }^{1}$. Entre os três presidentes eleitos diretamente pelo povo desde 1985, dois se autodenominaram de esquerda, Fernando Henrique Cardoso e Luiz Inácio Lula da Silva, e apenas um aceitava ser de direita, Fernando Collor. É verdade que nem todos os parlamentares desses partidos podem ser considerados de centro-esquerda: alguns, inclusive entre os do PT, depois que se tornou governo, são antes de centro-direita, mas os programas e as mensagens políticas que passam são de centro-esquerda.

O motivo pelo qual no Brasil os partidos e os candidatos presidenciais de esquerda tendem a ser eleitos com mais freqüência do que os de direita é evidente. Está diretamente

${ }^{1}$ Não lograram, todavia, maioria no Senado. 
relacionado com a brutal desigualdade social existente no país. Essa desigualdade, somada aos baixos níveis de educação e de formação cívica do povo brasileiro, fazem o eleitor esperar dos políticos um discurso voltado para uma maior distribuição de renda. Os políticos de esquerda podem fazer isso naturalmente, sem necessariamente serem populistas; já os candidatos de direita só são capazes de formular um discurso dessa natureza sendo populistas. Os candidatos de direita que ganham eleições executivas no Brasil são quase invariavelmente políticos populistas e demagógicos, que fazem um discurso que não corresponde a suas convicções. Já os candidatos de esquerda podem ser mais autênticos, embora não estejam livres do populismo.

Entretanto, uma vez eleitos, nem o presidente, nem os parlamentares de esquerda fazem um governo de esquerda, ou seja, que efetivamente contribua para a redução da injustiça social no país. Podem incluir em suas administrações algumas políticas sociais redistributivas, atendendo assim à pressão dos pobres; seus governos, porém, promoverão principalmente os interesses dos ricos, e a renda e a riqueza continuarão a se concentrar.

Por que os partidos de esquerda não governam em nome da esquerda no Brasil e, eu suponho, na América Latina? Não é porque um governo de esquerda seja impossível em países capitalistas. As experiências européias não deixam dúvida a respeito da viabilidade de governos de esquerda governando o capitalismo. Por que, então, no Brasil não tem sido viável, ainda que os eleitores elejam candidatos de esquerda ou, pelo menos, com um discurso de esquerda? A resposta mais geral a essa questão está no fato de que, no Brasil, como nos demais países em desenvolvimento, há um grande descompasso entre o "povo" e a "sociedade civil", e é nesta última que está sempre o verdadeiro poder político nas democracias. Destaquei as duas expressões porque as estou usando em um sentido muito preciso: povo, aqui, é o conjunto de cidadãos iguais perante a lei, dotados cada um do direito de um voto; sociedade civil é esse 
povo no qual, porém, o poder de cada cidadão é ponderado pelo dinheiro, conhecimento e capacidade de organização que ele detém. Não estou, portanto, confundindo sociedade civil, que é um conceito clássico, com "organizações da sociedade civil”, principalmente organizações públicas não-estatais de advocacia políticas - as chamadas ONGs stricto sensu - que são a base da lenta transição das atuais democracias de opinião pública para as democracias participativas. Enquanto o conceito de organizações da sociedade civil permite o desenvolvimento de uma teoria de emancipação social através da emergência da democracia participativa ou da democracia deliberativa, o conceito de sociedade civil não tem caráter normativo ${ }^{2}$. Sugere apenas que a sociedade politicamente organizada - ou seja, a sociedade civil - tende a ser mais conservadora, e talvez seja menos democrática do que o povo, porque nela aqueles indivíduos que possuem mais capital, mais conhecimento técnico, organizacional e comunicativo, e estão inseridos em organizações, sejam elas corporativas ou públicas não-estatais, terão individualmente mais poder do que os cidadãos comuns.

Quanto mais avançada for uma democracia, mais democratizada será sua sociedade civil, e, por isso mesmo, menor será a diferença entre ela e o povo ${ }^{3}$. Enquanto, no caso de uma sociedade civil autoritária, ela própria não se distingue com clareza do conceito de elites, a distinção é clara no caso de sociedades civis democráticas. Entende-se aqui por uma sociedade civil mais democrática exatamente aquela na qual as diferenças de poder de seus participantes em relação ao poder de cada cidadão no povo são menores. Ora, isso acontecerá à medida que, em cada sociedade, aumentar o grau de igualdade de renda, de conhecimento, de capacidade de organização, e, portanto, de poder político real. Ou seja,

\footnotetext{
${ }^{2}$ Esse conceito de sociedade civil, porém, foi muito útil para a análise que fiz, na segunda metade dos anos 1970, da transição democrática que começava então.

${ }^{3}$ Para uma excelente resenha do debate sobre as organizações da sociedade civil que surgiram como uma alternativa emancipadora nos anos 1990, ver Lavalle (2003).
} 
aumentar o grau de justiça social existente nessa sociedade. Isso mostra que, embora liberdade, garantida pela democracia, e justiça, trazida pelo crescente respeito aos direitos sociais, sejam objetivos políticos independentes, a teoria política indica que afinal são também interdependentes quando pensamos em termos de graus de liberdade e em graus de justiça. Em sociedades como a sueca ou a suíça, em que as desigualdades são relativamente pequenas, a sociedade civil é fortemente democrática, diferenciando-se pouco do povo. Assim, nessas sociedades, uma vez eleito pelo povo um governo de esquerda, esse governo, que reflete o poder da sociedade civil, fará uma administração de esquerda.

Enquanto isso, em sociedades menos democráticas e menos justas, como são as latino-americanas, o descompasso entre o povo e a sociedade civil é enorme. O povo não tende necessariamente a ser mais democrático do que a sociedade civil, como bem mostram as pesquisas sobre o tema realizadas por entidades como o Latinobarômetro, mas tende a ser mais de esquerda, na medida em que demanda do Estado políticas ativas mais distributivas. Dado esse descompasso, uma vez eleito um governo de esquerda, a tendência dos novos governantes, para alcançar "legitimidade" política junto à sociedade civil, será a de identificar-se rapidamente com as percepções e valores centrais dessa sociedade que é a fonte real de legitimidade. A fonte da legalidade política, nas democracias, é sempre o povo, mas a da legitimidade é dada antes pelo apoio da sociedade civil. Observe-se que essa afirmação que faço, como quase todas as demais, obedece a um critério histórico antes que normativo. Do ponto de vista normativo, seria melhor que legitimidade e legalidade se confundissem; mas, nesse caso, bastar-nos-ia apenas um conceito. Por isso, com base em Weber, uso o conceito de legitimidade para indicar o fato de que um governo conta com o apoio da sociedade civil, enquanto emprego o conceito de legalidade para dizer que ele foi eleito regularmente pelo povo. O primeiro é um 
conceito real - sociológico e histórico; o segundo, um conceito formal - jurídico no sentido estrito desta palavra. Quando o governo está recém-eleito, a tendência será a legalidade e a legitimidade política coincidirem, mesmo que o governo eleito seja de esquerda, e não tenha contado na eleição com o apoio da sociedade civil. Isso porque, eleito o novo governo, a sociedade civil tenderá a dar um voto de confiança aos novos governantes. Entretanto, a sociedade civil, e principalmente seus componentes mais à direita, esperam que o novo governo, ainda que conserve uma retórica de esquerda, revele rapidamente seu respeito pela propriedade e pelos contratos - pela ordem estabelecida, portanto - e que não adote políticas redistributivas fortes. Caso contrário, o governo correrá o risco de perder seu apoio.

\section{Os empresários e a esquerda}

Não há obstáculo para um empresário ser de esquerda, desde que a esquerda que apóie não seja revolucionária. Ele talvez precise de algum espírito republicano para sê-lo, mas não muito, porque no longo prazo é bem possível que ele saia ganhando com a política distributivista e defensora das liberdades que o governo de esquerda por ele apoiado provavelmente adotará. Poderá sair ganhando se a redução da desigualdade reduzir a instabilidade política, e, em conse-qüência, acelerar o processo de desenvolvimento econômico (Przeworski e Curvale, 2005). Poderá também sair ganhando se a política de intervenção moderada do Estado, patrocinada pelo governo, contribuir para o desenvolvimento. Caso, entretanto, tenha espírito republicano, mesmo sem se beneficiar pessoalmente, o empresário poderá ser de esquerda, desde que seu partido, uma vez no governo, seja capaz de governar o capitalismo de modo mais competente do que os capitalistas.

Para o empresário, o partido de esquerda ideal é aquele que busca reformar o capitalismo. A social-democracia foi a primeira forma que assumiu a esquerda quando deixou de ser 
revolucionária. Hoje, os partidos políticos de centro-esquerda, que foram inicialmente social-democráticos, tendem cada vez mais a tornar-se social-liberais. $\mathrm{O}$ social-liberalismo representa uma superação positiva da social-democracia, mas é naturalmente objeto de desconfiança da esquerda burocrática e da utópica. Da mesma forma que a social-democracia foi por muito tempo acusada de trair os ideais do socialismo, agora, acusase o social-liberalismo de trair os ideais da social-democracia. Entretanto, ser social-liberal é hoje quase que uma condição para o êxito de um partido de esquerda no governo. Hoje, os países que apresentam governos de esquerda mais bem-sucedidos, como é o caso dos países escandinavos, da Holanda e da Grã-Bretanha, estão deixando de ser social-democratas para serem social-liberais. A diferença fundamental entre a socialdemocracia e o social-liberalismo não está na defesa dos direitos sociais, mas no papel maior dado ao mercado e à competição na coordenação da economia e da própria organização do Estado e dos serviços sociais e científicos que financia.

\section{Esquerda e nação}

No caso da América Latina, o programa de um partido de esquerda na América Latina deverá necessariamente combinar a luta pela diminuição das desigualdades com a luta pelo desenvolvimento. A esquerda radical tende a acreditar que o desenvolvimento está assegurado no capitalismo, preocupando-se apenas com a distribuição; mas isso é um equívoco. Embora seja verdade que, para os países que se desenvolveram originalmente e completaram sua revolução industrial, o desenvolvimento capitalista tenda a ser auto-sustentado ${ }^{4}$, isso não é verdade para os países que foram submetidos a processos de imperialismo. Nesse caso, suas elites dependentes tornaram-se ambíguas em relação aos interesses nacionais porque, ao mesmo tempo em que se identificavam com esses interes-

\footnotetext{
${ }^{4}$ Furtado (1961).
} 
ses, eram ideologicamente subordinadas ao centro desenvolvido. Entretanto, quando se adota o desenvolvimento econômico como um objetivo, não há outra alternativa senão pensar em estratégias nacionais de desenvolvimento. Desde que nos anos 1980 a onda ideológica e globalista se tornou dominante, as elites conservadoras no continente subordinaram-se de forma indiscriminada às recomendações vindas de Washington e Nova York. Ora, o desenvolvimento econômico é sempre o resultado de uma estratégia que cada nação define com autonomia. Por isso, os países asiáticos que preservaram ciosamente essa autonomia são países dinâmicos, enquanto os da América Latina, que se inclinaram diante das pressões vindas do Norte, mantiveram-se semi-estagnados. Para os empresários nacionais, portanto, poderá ser interessante participar de governos de esquerda, os quais têm revelado maior capacidade para identificar-se com os interesses nacionais. As estratégias nacionais de desenvolvimento variarão muito de país para país. Os 94 países maiores serão mais voltados para o mercado interno do que os países pequenos. Mas nenhum deles pode partir do pressuposto globalista de que os países ricos cuidarão de seus interesses. No capitalismo global, em que a competição entre os Estados-nação é o princípio organizador do sistema, essa possibilidade não existe. Ou os partidos centro-esquerda, além de social-liberais, são nacionalistas (como, aliás, o são todos os partidos que nos países centrais disputam realmente o poder), ou não se desenvolverão.

O interesse e a capacidade de promover o desenvolvimento econômico, como o de promover a liberdade, não distinguem a esquerda da direita. Naturalmente, cada um dos agrupamentos políticos afirmará que é mais capaz tanto de uma coisa como de outra; mas, historicamente, vimos governos de direita e de esquerda sendo bem-sucedidos e sendo desastrosos em relação a esses dois objetivos políticos. Entretanto, nesta seção, argumentarei que, quando se pensa na definição de esquerda em países em desenvolvimento, é preciso incluir a 
idéia de desenvolvimento como um objetivo básico, e as idéias de nação e de interesse nacional como meios para alcançar esse objetivo. Historicamente, na Europa do século dezenove e de Marx, a burguesia era nacionalista e a esquerda, internacionalista. $\mathrm{O}$ internacionalismo da internacional socialista, porém, nunca convenceu os trabalhadores, que não hesitaram em, de alguma forma, associar-se à burguesia e aos técnicos do governo, quando se tratava de competir internacionalmente. Isso permitiu que todos os países capitalistas bem-sucedidos no plano econômico ao mesmo tempo consolidassem o projeto de construção de seus Estados-nação. Uma nação só ganha coesão e força, e o Estado só se torna o instrumento de ação coletiva dessa nação, se as classes sociais, não obstante seus conflitos, são capazes de tornar-se solidárias quando se trata de competir com outras nações. No momento, porém, em que a construção nacional e o desenvolvimento se consolidaram naqueles países do Norte, o nacionalismo, embora se mantendo dominante, deixou de ser uma ideologia expressa para se tornar subentendida. O nacionalismo, em sua condição de ideologia da construção do Estado-nação, implica atribuir-se aos governos a responsabilidade de defender o trabalho, o conhecimento e o capital nacionais. Hoje, nesses países, como nos países dinâmicos da Ásia - e muito diferentemente do que acontece nos países dependentes da América Latina - praticamente ninguém tem dúvida de que esse é o dever de seus governos, de forma que se tornou desnecessário reafirmar o próprio nacionalismo, transformado em valor consensual. Tornou-se, então, possível ocultar essa perspectiva, que sempre é incômoda nas relações internacionais, e reservar o adjetivo "nacionalista" para as perversões do nacionalismo, para suas expressões extremadas e violentas como o nazismo, ou para formas de populismo de direita ou de esquerda em países em desenvolvimento. Para os países ricos, esse ocultamento que naturalmente se processou tem a vantagem não prevista de neutralizar o eventual nacionalismo dos países em desenvolvimento, tornando suas elites 
mais dóceis às diretrizes vindas do Norte, principalmente às políticas de seu interesse de caráter econômico.

Já no caso dos países em desenvolvimento, e particularmente dos países da América Latina, não faz sentido ignorar o nacionalismo, porque ele está longe de se haver tornado consensual e de poder, portanto, ser subentendido. As elites da região - econômicas e intelectuais - são em grande parte dependentes. Foram nacionalistas em diversos graus e com graus diferentes de êxito entre 1930 e 1960. Getúlio Vargas, no Brasil, talvez tenha sido o modelo de estadista industrializante e nacionalista. Entretanto, essas elites, com a ameaça da revolução cubana de 1959, subordinaram-se ao Norte. A adoção da "teoria da dependência", seja na sua versão marxista radical, seja na versão também marxista, porém mais moderada da "dependência associada", não foi motivo para que se tornasse mais nacionalista, como se poderia imaginar; pelo contrário, foi motivo para que copiasse a clássica perspectiva internacionalista da esquerda européia do século XIX. Partindo do pressuposto de que na América Latina não seria possível haver uma "burguesia nacional", a primeira versão da teoria da dependência concluiu pela revolução socialista, e a segunda, pela associação ou subordinação aos países ricos ${ }^{5}$. Em ambos os casos, a idéia de nação ficava automaticamente rejeitada. A ascendência dessas duas interpretações sobre as esquerdas na América Latina, além de dificultar uma aproximação das esquerdas com os empresários, levouas a tornarem-se cosmopolitas. A própria prioridade dada ao desenvolvimento econômico foi perdida pela esquerda, uma vez que esta assumiu que, no capitalismo, o desenvolvimento ocorreria de qualquer maneira, de forma que caberia a ela se preocupar com a democracia e a justiça social. Com a crise da dívida externa dos anos 1980, a dependência dos países latino-americanos aprofundou-se. Isso ocorreu por-

${ }^{5}$ Bresser-Pereira, "Do Iseb e da Cepal à teoria da dependência" (2005). 
que o antigo modelo nacional-desenvolvimentista, que fora bem-sucedido em promover a industrialização do país entre 1930 e 1980, entrou em crise. Ocorreu, também, porque a pressão ideológica globalista vinda do Norte, afirmando que na era da globalização o Estado-nação perdera relevância e anunciando a governança global em um mundo sem fronteiras, tornou-se fortíssima a partir daquela mesma data. $\mathrm{E}$ ocorreu, finalmente, porque as elites latino-americanas, conservadoras e dependentes, principalmente aquelas ligadas ao setor financeiro, aderiram rapidamente às novas idéias. Dessa forma, os países latino-americanos, inclusive o Brasil, que entre os anos 1930 e 1980 estavam realizando suas revoluções nacionais, viram essa construção ser interrompida ${ }^{6}$.

Hoje, porém, quase 20 anos depois do fim da Guerra Fria, e dado o fracasso das políticas neoliberais em promover o desenvolvimento da América Latina, seria razoável esperar que, nos países latino-americanos, a esquerda fosse nacional e tivesse como prioridade o desenvolvimento econômico nacional. Sem uma atitude nacionalista democrática e liberal, mas não neoliberal, os países de desenvolvimento médio não lograrão evitar a dominação vinda do Norte, não lograrão realizar as reformas institucionais e adotar as políticas econômicas que são realmente necessárias para seu desenvolvimento. Nos últimos 25 anos, porém, os países asiáticos dinâmicos demonstraram que é possível usar com moderação o nacionalismo para construir seus Estados nacionais e para promover com êxito seu desenvolvimento. Serão os países latino-americanos capazes de fazer o mesmo? Se formos depender de seus intelectuais, dificilmente. Na região, os intelectuais são particularmente dependentes, como o demonstraram ao formular teorias da dependência equivocadas. Fazem o que é inerente à situação de dependência não criticada: copiam o internacionalismo das esquerdas européias, não se dando conta de que estas só ado-

\footnotetext{
${ }^{6}$ Celso Furtado (1992).
} 
taram o internacionalismo em teoria, enquanto se associavam aos empresários na construção da nação e na participação em estratégias nacionais de desenvolvimento.

É preciso, entretanto, considerar que, além das duas teorias da dependência mais conhecidas - a da super-exploração capitalista e a da dependência associada -, existe uma terceira que faz mais sentido: a teoria do desenvolvimento nacional-dependente ${ }^{7}$. Por meio desse oxímoro, o que se pretende acentuar é o caráter intrinsecamente ambíguo e contraditório das elites latino-americanas, que são dependentes dos Estados Unidos, mas têm interesses reais relacionados com suas respectivas nações. Em certos momentos, como aconteceu entre os anos 1930 e os anos 1950, os interesses nacionais prevalecem, inclusive porque o centro estava em crise; em outros, como aconteceu nos anos 1980 e 1990, a dependência torna-se dominante. Resta saber o que acontecerá nos anos 2000. Metade da década já passou, e algumas tendências na 98 direção da esquerda e da nação são visíveis, mas é cedo ainda para se afirmar qualquer coisa com segurança.

\section{Conclusão}

Nos últimos anos, diante do fracasso das reformas e políticas neoliberais em promover o desenvolvimento da região, notase, por parte mais dos empresários do que dos intelectuais, um interesse maior pelas questões nacionais, e uma maior disponibilidade para apoiar partidos de esquerda moderados que tenham um compromisso com o desenvolvimento nacional. Enquanto os empresários e a burocracia do Estado são mais facilmente nacionalistas do que de esquerda, os intelectuais tendem a ser mais de esquerda do que nacionais. A aliança fundamental que constitui uma nação é sempre a da burguesia com a burocracia do Estado, enquanto nos intelectuais e nos trabalhadores se encontram as bases principais da esquerda.

\footnotetext{
${ }^{7}$ Bresser-Pereira (1992).
} 
Caso esses dois grupos venham a associar-se, como é possível que agora aconteça, pode-se esperar, assim, que um nacionalismo democrático e social-liberal ganhe força na região e passe a caracterizar os partidos de centro-esquerda. Se isso de fato acontecer, os empresários progressistas terão nesses partidos políticos um espaço privilegiado para sua ação política. A eleição de presidentes de esquerda e, eventualmente, nacionalistas na América Latina nos últimos anos é uma indicação dessa mudança. Não há, entretanto, segurança de que sejam bemsucedidos e promovam os dois objetivos que legitimariam seus governos democráticos: retomar o desenvolvimento econômico e promover a melhoria da distribuição de renda. No Brasil, o presidente Luiz Inácio Lula da Silva, embora apoiado em um partido forte, fracassou. Subordinou-se à coalizão dominante no Brasil - dos rentistas e do setor financeiro, interessados em juros escandalosamente altos, associados às empresas multinacionais e aos exportadores para o Brasil, interessados em taxa de câmbio valorizada - e manteve a política macroeconômica perversa de juro alto e câmbio baixo. Além disso, o PT comprometeu-se com um sistema de corrupção generalizado. Na Venezuela, Hugo Chávez continua a ser uma alternativa muito melhor do que a direita corrupta e cosmopolita que lhe faz oposição, mas sua incontinência verbal e suas tendências autoritárias são preocupantes. No Uruguai e na Bolívia, temos incógnitas. Apenas na Argentina, sob a liderança do presidente Néstor Kirchner, a esquerda nacional vem realizando avanços na direção do bom governo.

Está claro que a América Latina precisa de um novo desenvolvimentismo para superar a semi-estagnação dos últimos 25 anos e enfrentar os desafios do atual estágio de desenvolvimento de cada um de seus países. O neoliberalismo fracassou, e só uma política econômica que combine estabilidade macroeconômica com promoção ativa da competitividade internacional e do desenvolvimento poderá substituí-lo. Uma política dessa natureza será o novo-desenvolvimentismo 
a que me refiro, que tem nos partidos de centro-esquerda da América Latina seu respaldo natural. Se esses partidos contarem com o apoio de empresários progressistas e nacionais, as possibilidades que terão de evitar os dois grandes problemas que assolam a política na América Latina - o populismo econômico e a subordinação aos interesses de rentistas e multinacionais - aumentarão substancialmente.

\section{Luiz Carlos Bresser-Pereira}

é professor da Fundação Getúlio Vargas, São Paulo, e editor da Revista de Economia Política

\section{Referências bibliográficas}

AGUITON, Christophe et al. 2003. Où Va le Mouvement Altermondialisation? Paris: La Découverte.

BRESSER-PEREIRA, Luiz Carlos. 2005. "Do Iseb e da Cepal à teoria da dependência”. In: TOLEDO, Caio Navarro de (Org.). Intelectuais e política no Brasil: a experiência do ISEB. Rio de Janeiro: Revan. p. 201-232.

100 DIMOSER, Ditmar. 2005. "Democracia sin democratas: sobre la crisis de la democracia en América Latina”. Nueva Sociedad, n. 197, p. 28-40.

FURTAD0, Celso. 1961. "O processo histórico do desenvolvimento”. Desenvolvimento e Subdesenvolvimento, Capítulo 3. Rio de Janeiro: Fundo de Cultura, 1961. In: BRESSER-PEREIRA; REGO. A grande esperança em Celso Furtado. São Paulo: Editora 34, 2002 (republicação).

FURTADO, Celso. 1992. Brasil: a construção interrompida. São Paulo: Editora Paz e Terra.

LAVALLE, Adrián Gurza. 2003. "Sem pena nem glória: o debate sobre a sociedade civil nos anos 1990". Novos Estudos Cebrap, n. 66, p. 91-109, julho.

LOZANO, Wilfredo. 2005. "La izquierda latinoamericana en el poder". Nueva Sociedad, n. 197, p. 129-145.

PRZEWORSKI, Adam; CURVALE, Carolina. 2005. "Does politics explain the economic gap between the United States and Latin America?" Nova York: New York University, Department of Politics, October 13.

SINGER, André. 1999. Esquerda e direita no eleitorado brasileiro. São Paulo: Edusp. 


\section{ESQUERDA NACIONAL E EMPRESÁRIOS NA AMÉRICA LATINA}

\section{LUIZ CARLOS BRESSER-PEREIRA}

Pode um empresário fazer parte de um partido político de esquerda? Para responder a essa pergunta, o autor define esquerda como a ideologia política que aceita arriscar a ordem social em nome da justiça social. Se isso é feito moderadamente, se o partido político adota uma posição de centro-esquerda, não haverá inconsistência. Nas democracias modernas, os partidos políticos da esquerda e da direita lutam por apoio do centro ideológico e tendem a convergir para ele. O que dizer sobre o assunto no caso do Brasil? Aqui, como nos outros países da América Latina, os partidos políticos de esquerda moderados freqüentemente vencem as eleições, mas raramente governam. Esse paradoxo é explicado pelo caráter conservador das elites latino-americanas. A América Latina é formada por países dependentes que competem em um mundo em que as estratégias nacionais são necessárias para o crescimento. Em princípio, espera-se que a esquerda seja uma esquerda nacional; mas, desde que a "teoria da dependência" declarou que a burguesia nacional era "impossível" na América Latina, uma aliança entre empresários progressistas e a esquerda torna-se mais difícil, ao mesmo tempo que a esquerda e os intelectuais tendem a tornarem-se dependentes ou cosmopolitas.

Palavras-chave: Esquerda, direita e centro; Partidos políticos; Dependência nacional 


\section{NATIONAL LEFT AND BUSINESS CLASS IN LATIN AMERICA}

May a business man support a left wing political party? To answer this question, the author defines left as the political ideology that accepts to risk social order in name of social justice. If this is done moderately, if the political party adopts a center-left position, there will be no inconsistency. In modern democracies, political parties on the left and on the right fight for the support of the ideological center, and tend to converge to it. What to say on that question in the case of Brazil? Here, as in Latin America, moderate left-wing political parties often win elections but seldom govern. This paradox is explained by the conservative character of Latin American elites. Latin America is formed of dependent countries striving in a highly competitive world where national strategies are required to grow. In principle, one would expect that the left would be a national left, but since the "dependency theory" declared that a national bourgeoisie was impossible in Latin America, an alliance between progressive business men and the left became more difficult but, also, the left and the intellectuals tended to become dependent or cosmopolitan.

Keywords: The left, the right and the center; Political parties; National dependency. 